\title{
A FORMAÇÃO DA CONFIANÇA: UM ESTUDO NO POOL DA UNIBRASPE
}

\author{
THE FORMATION OF TRUST: \\ A STUDY IN THE UNIBRASPE'S POOL
}

Recebido em 30.03.10 / Aceito em 14.09.10

Sérgio Luiz Pirani ${ }^{1}$ e Cleverson Renan da Cunha ${ }^{2}$

\section{Resumo}

O tema de estudo deste trabalho é a formação da Confiança no pool da UNIBRASPE. O objetivo foi identificar a estrutura e a evolução dos relacionamentos interorganizacionais. A evolução da confiança foi detectada por meio de observações, entrevistas semiestruturadas e questionários. Esta pesquisa caracteriza-se como um estudo de caso descritivo-analítico. A partir dos resultados obtidos, concluiu-se que a estrutura da rede é um condicionante para o bom relacionamento entre seus pares, permitindo que normas formais e informais contribuam para a gestão do pool. Além disso, foi possível reconhecer que a evolução da confiança é estabelecida pelo conhecimento prévio dos atores estudados e que resulta em um relacionamento mais estreito entre essas organizações.

Palavras-chave: Relacionamento Interorganizacional. Confiança. Governança.

\footnotetext{
1 Graduado em Administração pela Fundação Faculdade Estadual de Educação Ciências e Letras de Paranavaí (2001); mestrado em Administração, pela Universidade Federal do Paraná (Minter). É professor universitário na Faculdade Educacional Araucária (FACEAR, PR) e Faculdades Integradas Camões (FICA), Curitiba,PR.

2 Graduado em Administração pela Universidade Federal do Espírito Santo (1995), mestrado em Administração pela Universidade Federal do Paraná (2001) e doutorado em Administração pela Universidade Federal de Minas Gerais (2004). Atualmente é professor adjunto do Centro de Pesquisa e Pós-Graduação em Administração da Universidade Federal do Paraná.
} 


\begin{abstract}
The theme of this work is the formation of Trust in the UNIBRASPE's pool. The objective of this assignment was to identify the structure and evolution of interorganisational relationships. The evolution of trust was detected through observation, semi-structured interviews and questionaires characterizing this survey as a descriptive-analitical case study. We can conclude that the structure of the network is a condition for good relationships between its members, permitting formal and informal norms complement to the pool's gestation. It was also noted that the evolution of trust came about through the previous knowledge of the people studied which made it possible for their to be a closer relationship between the organizations.

Keywords: Network Relationship. True. Governance.
\end{abstract}

\title{
1 INTRODUÇÃO
}

Na última década, o contexto das organizações foi permeado pela competitividade e a instabilidade ambiental. Somam-se a esse panorama a crescente agressividade das grandes corporações por novos mercados consumidores e ou produtores de matéria-prima. Tal cenário preocupa as pequenas e microempresas, pois muitas não dispõem de estrutura econômica para confrontar as grandes corporações em igual patamar. Diante dessas circunstâncias, tais empresas foram induzidas a formularem novas estratégias para que se mantivessem no mercado, entre elas está aquela que valoriza o interesse comum entre empresas: a Aliança de Serviços, as Alianças Oportunistas e as Alianças de Stakeholders - assim classificadas por Kanter (1990).

No primeiro grupo, encontra-se o tipo de relacionamento interorganizacional mais estreito: o pool, que é aquele concebido como uma unidade administrativa que presta determinado serviço a toda uma organização. (FERREIRA, 2004). Essa relação é estabelecida por meio de um item essencial: a confiança. Acorda-se que sua subjetividade deve ser recíproca, pois é necessário confiar no relacionamento e ter atitudes para demonstrá-la. A partir de então, tem-se um importante mecanismo de interação nos relacionamentos organizacionais. (CUNHA, 2004).

\section{BASE TEÓRICO-EMPÍRICA}

\section{A cooperação em redes interorganizacionais}

A competitividade oriunda da abertura econômica não permite mais uma visão insular da organização. Diante desse fato, são válidas e fundamentais as práticas para que haja melhor relacionamento e cooperação entre as empresas que compõem uma rede. Como indica o estudo de Malafaia et al. (2007), o sucesso nesses relacionamentos é pautado por uma forte cultura de colaboração entre os participantes do grupo cooperativo ou da empresa, e tal comprometimento é fator fundamental para o sucesso das ações coletivas.

Além disso, é necessário que coexistam confiança e capital social para que sejam maiores as chances do empreendimento atingir resultados positivos, principalmente quando a criação de regras e instrumentos formais é desenvolvida em conjunto pelos participantes, reforçando a confiança do grupo e reduzindo a possibilidade de comportamentos oportunistas. (MALAFAIA et al., 2007). O conceito de cooperação entre empresas e de distritos industriais já estava evidenciado nos escritos de Marshall, em 1925, que tratam das aglomerações industriais nas imediações 
das grandes cidades, bem como entre as diferentes empresas que cooperam em ramos associados de produção e distribuição.

Após os estudos de Marshall, Brusco (1982) apresentou a dinâmica das interações entre as estruturas de produção, o mercado de trabalho e as principais políticas que foram instituídas na Emília-Romagna, na Itália. Além disso, observou a descentralização e uma integração social causada pela cooperação interfirmas e ao adotarem a estratégia de cooperação em rede onde se tem a empresa-centro (hub firm) e em sua vizinhança toda uma rede. Os recursos ficaram disponibilizados a essa e permitiu-se o acesso de seus membros à hub firm. Essa passou a ser a provedora dos principais recursos e fiscalizadora das demais empresas, tornando-se uma solução viável àquelas que não viam a possibilidade de competir num mercado internacionalizado (BRUSCO, 1982; AMATO NETO, 2005).

Outra forma de interrelacionamento é a baseada na dependência de recursos numa suposição de que nenhuma empresa é capaz de gerar todos os recursos distintos de que necessita (ROSSETTO; ROSSETTO, 2005), por isso busca esses recursos (capital, tecnologia, conhecimento gerencial etc.) em outras organizações, para que se mantenham em mesmo grau de competição no mercado.

Numa categorização de estratégias vistas como tipos genéricos, Pfeffer e Salancik (1979) e Kotter (1979) descreveram três tipologias. A primeira pode ser compreendida como a capacidade da organização de reorganizar o seu ambiente para reduzir sua dependência externa por meio de expansão de domínios, integração vertical, integração horizontal, diversificação, fusão ou aquisição. A segunda tipologia descreve a negociação da dependência para estabelecer relações cooperativas por meio de acordos como cartéis e joint ventures. A terceira está apoiada em instâncias governamentais e canais judiciais, embasada em ações legais contra os concorrentes, podendo ser amparada por subsídios, introdução de novas tarifas ou outras formas de regulação do setor. Compreende-se, dessa forma, que um pool é uma estratégia de interrelacionamento entre as organizações que pode ser compreendido como sendo um conjunto de pessoas ou entidades que unem esforços ou recursos para alcançar um objetivo comum. (MICHAELIS, 1998; FERREIRA, 2004).

\section{Cooperação e competição}

A estratégia colaborativa nos relacionamentos interorganizacionais, de acordo com Riolo, Cohen e Axelrold (2001), é um artifício para que empresas inseridas nesse modelo consigam atingir seus objetivos com menores custos e esforço. Há alguns modelos peculiares de relacionamento, como o sugerido por Castells (1999), denominado redes multidirecionais, postos em prática por empresas de pequeno e médio porte, e o modelo de licenciamento e subcontratação de produção sob o controle de uma grande empresa. O primeiro modelo de Castells (1999) é baseado em redes de pequenos negócios domésticos que formam redes de produção e distribuição e que, conforme os sinais das necessidades dos intermediários, realizam a produção. O segundo modelo é baseado na hub firm, tendo como principal exemplo a rede produtiva chamada de "Modelo Benetton". Ela era a empresa controladora dos processos, fiscalizadora da qualidade dos produtos e encarregada da distribuição e controle de estoques de toda a rede franqueada para a distribuição de seus produtos (CASTELLS, 1999; AMATO NETO, 2005). Numa outra perspectiva, as relações cooperativas entre atores verticais, como vendedores e compradores, são mais fáceis de compreender, pois são construídas sobre uma distribuição das atividades e de recursos entre seus pares em uma cadeia de abastecimento, como afirmam Bengtsson e Kock 
(1999). Por outro lado, esses autores enfatizam que as relações horizontais são mais informais e invisíveis, e são categorizadas em quatro grupos diferentes, dependendo da natureza e dos fluxos nos relacionamentos:

- Na coexistência: a relação não inclui qualquer intercâmbio econômico, mas apenas informações e relações sociais, há neste contexto baixa cooperação e baixa competição entre os envolvidos. A confiança, embora informal, é considerada alta, já que um ator depende do outro, mas sem haver interferência e os objetivos são convencionados de maneira independente. Ressalta-se que as normas, embora sejam informais e as regras do jogo não sejam discutidas, são bastante fortes nos relacionamentos.

- Na cooperação: os competidores têm objetivos comuns e as trocas entre as empresas são freqüentes, incluindo informações, laços econômicos, comércio e trocas sociais. Apesar de os concorrentes cooperarem uns com os outros, isso não anula a concorrência entre si, há inclusive desconfiança entre os atores. Por outro lado, há poucos conflitos. Isso indica a construção de acordos informais sobre as normas sociais e de confiança, mas essas normas são, por vezes, formais com intuito de ajustar a distribuição de poder e dependência entre os concorrentes;

- Na competição: surge uma ação e reação padrão na medida em que os concorrentes se perseguem. A interação é simples e direta. Poder e dependência são equitativamente distribuídos entre as partes com base em suas posições na rede. As regras são baseadas em normas informais, e os competidores definem suas metas de maneira independente. Uma característica comum é que essas metas são semelhantes na estrutura e só podem ser alcançadas por meio da aquisição de recursos do mesmo comprador;

- Na coopetição: essa relação pode incluir tanto trocas econômicas como não-econômicas, nessa situação há alta cooperação e alta competição entre as partes. O poder é baseado em aspectos funcionais de acordo com a cadeia de valor, isso numa posição cooperativa, já numa posição competitiva, no relacionamento, o poder está baseado na posição e força do concorrente.

Os quatro tipos de relacionamentos horizontais são uma tentativa de explicar as mudanças nas relações entre os concorrentes, demonstrando que um ator precisa ter uma carteira de diferentes relacionamentos para que esses possam ser incorporados na conjuntura do momento. As alterações em relações verticais ou horizontais podem influenciar o conteúdo de outros relacionamentos. Desse modo, o conteúdo de um relacionamento pode mudar a partir da concorrência num determinado tempo e a cooperação, coexistência ou coopetição em outro. (BENGTSSON; KOCK, 1999).

Estrutura das redes de relacionamentos

Os modelos da concepção de estruturas organizacionais de relações são os que formam os conjuntos de funções e atividades conexas em redes. Caracterizam os níveis de interdependência, densidade da rede, tamanho da rede, motivação para o relacionamento, base que predominam os relacionamentos e a centralidade da rede. O nível de interdependência está na variedade de regras e suas implicações para o surgimento de configurações distintas. O grau de interdependência pode ser mensurado pelos números de programas conjuntos e quanto maior for esse número de programas mais a organização é limitada a obrigações, compromissos e contratos, esses processos podem incorrer na perda de poder e na faculdade de gerência dos participantes. (COSER, 2003). A densidade das redes é discutida, muitas vezes, em termos de proporção, pois indica a média e o nível de ligação entre os contatos e também a proporção de pares conectada com fortes vínculos. Dessa forma, a densidade da rede é determinada pela força média de conexão entre os contatos. (BURT, 2000). Knoke (1994) argumenta que a conve- 
niência de analisar o tamanho de uma rede está na totalidade de conexões que existe entre seus pares; desse modo, a mensuração do tamanho da rede é granjeada através das relações diretas entre os atores.

A motivação para o relacionamento diz respeito à socialização dos atores que tendem a interagir com outros que sejam semelhantes nas atitudes, recursos, competências e comportamentos. Dadas essas características, pode-se compreender que as empresas que estejam num mesmo contexto tenham grande simetria em seus perfis, como o ativo e o fluxo de informações. (EMIRBAYER; GOODWIN, 1994). Medidas de centralidade permitem identificar os grupos específicos que são mais importantes para a reforma da rede nas organizações. As origens desta ideia imediata é sociométrica e pode ser encontrada no conceito de star - que é a pessoa mais "popular" em seu grupo ou quem fica no centro das atenções. (SCOTT, 2000). A estruturação da rede abordada é parte distinta destas relações, que está sustentada na evolução da confiança entre seus pares na rede, e que só é possível se for sustentada por um mecanismo de governança que esteja voltado para essa realidade.

\section{Confiança: conceitos e evolução}

A variação de conceitos sobre confiança é sugerida por diferentes campos de estudos, como a psicologia, economia e a sociologia e, mais recentemente, a administração, no perímetro organizacional na gestão. O conceito de confiança, dado por Derbel e Mamrouk (2003), expõe a dificuldade de tal tarefa quando afirmam que é o processo do indivíduo vir a traduzir as diferentes percepções do seu sistema de discernimento unificado para qualificar o seu sentimento convertido em confiança. Na sua forma mais simples, a confiança pode ser vista como um ator que está disposto a aceitar ou expor a sua vulnerabilidade, em um antecedente de atitudes e comportamentos que permitam ações em condições de incerteza e risco. Nas organizações contemporâneas, a confiança é ainda crítica, pois o conhecimento e a interação do trabalho são caracterizados pela complexidade, a incerteza e o risco. Nesse ambiente, a confiança é definida pelas expectativas positivas entre os atores que compõem a organização.

A confiança cumpre um papel social, sem o qual não se poderia interagir. Esse não foi negado pelas ciências sociais contemporâneas, que consideram confiar um mecanismo informal, coordenador de ações e tem a vantagem de redução dos "custos de transação". Em contrapartida, a confiança relacional incorpora uma perspectiva social e baseia-se, pelo menos em parte, em prova produzida pela relação. (QUERE, 2001; XAVIER, 2007). Os benefícios da confiança nas relações interorganizacionais giram em torno dos seguintes pontos-chave: o nascimento da confiança pode trazer economia em termos de custos de transação. A confiança que permeia a relação entre seus pares, os recursos destinados ao controle e aos sistemas formais (processos de elaboração de contratos complexos e de verificação) é tornado menos necessário, diminuindo os custos de transações. Esses custos podem ser distinguidos como antes e depois da transação. Os primeiros podem ser considerados os custos de elaboração, negociação e salvaguarda de um acordo, que pode ser redigido num complexo documento, onde as partes devem estar de comum acordo. Os custos a posteriori assumem diversas formas como, por exemplo, os custos incorridos com descontos que são derivados de transações fora do escopo do contrato. (WILLIAMSON, 1985).

\section{PROCEDIMENTOS METODOLÓGICOS}

O estudo de caso foi o método de pesquisa adotado para o desenvolvimento deste trabalho, pois permite coletar informações por meio de observações e entrevistas, documentos e materiais visuais, bem como estabelecer um protocolo para registrar essas informações. (CRESWELL, 2007). 
A observação direta in loco, onde se manifesta o fenômeno, e conversação com o informante-chave foram usadas como fontes para o cruzamento das informações provenientes das entrevistas com os outros participantes, no intuito de corroborar as informações advindas das entrevistas. A investigação documental foi usada como fonte para granjear evidências e com o propósito de fortalecer as outras fontes já indicadas anteriormente. Os dados foram levantados por meio de entrevista semiestruturada com o gerente da UNIBRASPE, com duração de duas horas, e com outros três gerentes das empresas selecionadas.

Num primeiro momento foi aplicado um questionário para as dezessete empresas que compõem o pool, com a intenção de levantar os dados de relacionamento entre as empresas. Por meio das respostas sobre razão predominante e intensidade nos relacionamentos é que foram, então, selecionadas três empresas para análise da evolução da confiança. Para averiguar a evolução da confiança, foram realizadas entrevistas semiestruturadas com os gerentes das três empresas selecionadas para esta pesquisa. Esses encontros não ficaram limitados às respostas do questionário, pois foram investidos períodos de observação nas empresas, gravações de entrevistas e visitas adicionais para esclarecimentos sobre as respostas obtidas. Para as três empresas selecionadas, foi aplicado um questionário direcionado para prospectar dados sobre a evolução da confiança entre elas. Os questionários foram aplicados de forma separada para cada uma delas e, após a sua aplicação, foram realizadas visitas e entrevistas não estruturadas para validar o questionário.

A análise dos dados, aqui apresentada, tem característica qualitativa e busca apresentar o desenvolvimento do estudo realizado por meio das respostas dadas pelos integrantes da rede analisada. Foram tratados três assuntos pertinentes à pesquisa, sendo o primeiro a cooperação em redes interorganizacionais e sua estrutura de relacionamentos, o segundo o mecanismo de governança do pool e, por fim, a confiança nas relações e a categorização da evolução das bases da confiança. Antes, porém, é oportuno tratar o contexto da pesquisa realizada.

\section{Apresentação e análise dos dados}

O ramo de atividade de combustíveis líquidos foi caracterizado por um longo período por companhias que detinham bandeira exclusiva. Essas vendiam e distribuíam combustíveis para compradores varejistas que pertenciam à bandeira de determinada distribuidora e que as tinham como única alternativa de compra. A "bandeira", segundo a Agência Nacional de Petróleo (ANP, 2009), é a "marca comercial que indica a origem do combustível automotivo comercializado no posto revendedor varejista, isto é, identifica o distribuidor que fornece combustíveis líquidos derivados de petróleo, álcool combustível e outros combustíveis automotivos ao posto". Com a portaria ANP no 116/00, a ANP regulamentou a "bandeira branca", que é denominada por "postos revendedores varejistas que adquirem combustíveis de vários distribuidores diferentes e identificam o fornecedor do combustível em cada bomba abastecedora do posto" (ANP, 2009). Tal portaria foi regulamentada no ano de 2000 (ANP, 2009). Este cenário foi favorável para o surgimento do pool, que tem como estratégia suprir as necessidades das empresas que obedecem ao perfil descrito anteriormente.

O pool da UNIBRASPE foi constituído por cinco empresas sócias que, no início de suas atividades, não dispunham de todo o capital necessário para montar cada qual a sua base de distribuição. No entanto, com a soma de seus capitais, foi possível realizar o projeto da base de distribuição.

\section{A cooperação em redes interorganizacionais}

O principal argumento para a cooperação em redes está apoiado em ações do concorrente, relações duradouras entre as empresas e os resultados dessas relações. A estrutura desses relacionamentos está apoiada em cultura, conhecimento dos envolvidos e política. O conheci- 
mento está relacionado na dinâmica do desenvolvimento de uma melhor compreensão dos fenômenos competitivos. A política está relacionada aos sistemas de regras e a um conjunto de objetivos comuns que delimitam as ações dessas organizações e condicionam a sua consecução. A cultura relaciona-se aos hábitos e comportamentos de um grupo e/ou organização baseado em crenças, valores e atitudes. (MOTTA; CALDAS, 1997; GNYAWALI; MADHAVAN, 2001).

Diversos conjuntos atuam como antecedentes para a construção da preferência de um membro ou de uma empresa específica. Dentre esses, destacam-se aquele que é constituído pela prospecção do histórico da empresa alvo, numa orientação temporal. O outro compreende uma série de fatores situacionais comuns às empresas envolvidas e às similaridades que as atraem num interesse comum. (DAS, 2006). Os dados da pesquisa sobre o pool indicaram que, no início da relação, quando não havia um conhecimento prévio sobre o histórico de determinada empresa, todo o grupo apoiava-se em informações de mercado ou mesmo em informações dentro do próprio pool com as outras empresas que já se relacionavam com a empresa em jogo. A construção da preferência entre essas empresas foram firmadas nas respostas que indicam $\mathrm{o}$ modo que essas organizações fazem as escolhas. A empresa denominada A respondeu que "verifica bem o histórico da empresa perante aos seus fornecedores e clientes", a firma B apoia-se no fator "sorte" a C sustenta-se em informações advindas das outras organizações e informações do mercado respondendo que procura saber da "fama da outra empresa no mercado. Afirmando que confiança se conquista com o tempo", a firma $\mathbf{D}$ aposta na seriedade dessas organizações e que só tem essas informações com outras empresas com as quais aquela se relaciona.

A estrutura de relacionamento no pool indicou conjuntos de laços recorrentes, como, por exemplo, os recursos, a amizade e os laços informais entre um conjunto de atores, como indivíduos, grupos e as organizações do mesmo ambiente. Existem 17 empresas no pool, sendo 5 sócias e mais 12 congêneres. Para análise da rede numa relação baseada em confiança, foram selecionadas, por meio da pesquisa e observação, três empresas que se relacionassem com mais frequência e que tivessem mais similaridades entre si para a realização do trabalho.

O nível de interdependência é explicado por um sistema composto de $\mathbf{N}$ atores, numa rede de relações interorganizacionais, há duas perspectivas que podem ser visualizadas a partir da intensidade da relação entre dois atores dentro de uma única rede: (1) a partir da perspectiva dos dois atores como uma díade, que é secundariamente associada à rede global, ou (2) a partir da perspectiva dos atores como dois elementos da rede global. A primeira pode ser discutida em termos de uma distância assimétrica entre um indivíduo e outro. Esta última pode ser discutida em termos de uma distância simétrica social entre os dois atores, em termos de suas respectivas posições na rede. (BURT, 2000). A interdependência relatada entre as três empresas selecionadas para o estudo enquadra-se no segundo caso. No estudo geral, as trocas de informações foram atribuídas pela maior parte das empresas como as atividades mais intensas e são realizadas diariamente. Nas empresas selecionadas, a interdependência é maior e os relacionamentos estendem-se além das trocas de informações. Nos relatos dos informantes, a confiança é o alicerce dos relacionamentos. O ponto de iniciação desses foi o conhecimento pessoal prévio de cada um deles. No desenvolvimento do relacionamento, as informações ficaram mais estreitas e o auxílio passou a ser mútuo, tendo como principal propósito a redução de custos e a vantagem competitiva. A partilha de frete foi mencionada como um dos principais fatores para a redução de custos entre essas congêneres. A semelhança entre essas empresas foi um fator citado pelas três, relatando que têm os mesmos objetivos, confiabilidade, a busca de expansão de novos mercados e a seriedade nos negócios entre elas e os clientes. É relevante ressaltar que as entrevistas foram realizadas em separado com essas empresas e as respostas parecem sustentar as semelhanças.

A densidade da rede é determinada pela força média de conexão entre seus atores. Por vezes, é discutida em termos de proporção, porque, em estudos limitados a dados dicotômicos (há a possibilidade de duas pessoas estarem ligadas ou não), a força média da ligação entre os contatos é também a proporção de pares que estão conectados com fortes vínculos entre si. 
(BURT, 2000). Os dados para caracterizar a densidade nos relacionamentos, neste estudo, foram prospectados por meio da qualificação por grau de intensidade nos relacionamentos de uma organização com as demais. Esses graus foram mensurados com respostas que indicavam os seguintes pareceres: (1) Sem importância; (2) Pouco importante; (3) Importante; (4) Muito importante e (5) Crucial. Com os dados advindos das respostas, foi possível selecionar três empresas que mais interagiam na rede, ou seja, que tivessem um relacionamento mais denso. Essas empresas foram denominadas $\mathbf{A}, \mathbf{C}$ e $\mathbf{Q}$, para o estudo das suas relações centradas na confiança entre esses atores.

A análise de rede é apropriada para o estudo pormenorizado das relações baseadas em dados relacionais advindos da pesquisa. A característica geral dos dados das ciências sociais é que esses estão enraizados nos valores culturais e símbolos. Ao contrário dos dados físicos das ciências naturais, nas ciências sociais os dados são constituídos através de significados, motivos, definições e tipificações. Isto significa que a produção de dados nas ciências sociais envolve um processo de interpretação. (SCOTT, 2000).

A matriz para definir o tamanho da rede é disposta em linhas e colunas. Numa matriz contígua, a sua denominação é quadrada por dispor do mesmo número de linhas e colunas (ordem ou tamanho $\mathrm{Y} \times \mathrm{Y}$ ). No presente trabalho, a matriz dispõe dessa característica numa ordem de $17 \times 17$ (Figura 1). Para o roteiro da matriz da rede foi utilizada a seguinte questão: A empresa interage com alguma das empresas listadas a seguir? Marcar sim ou não para cada uma das organizações listadas. Se sim, marque como um $\mathbf{X}$ a periodicidade desta relação. Para cada uma das empresas participantes foi atribuída uma letra para sua identificação.

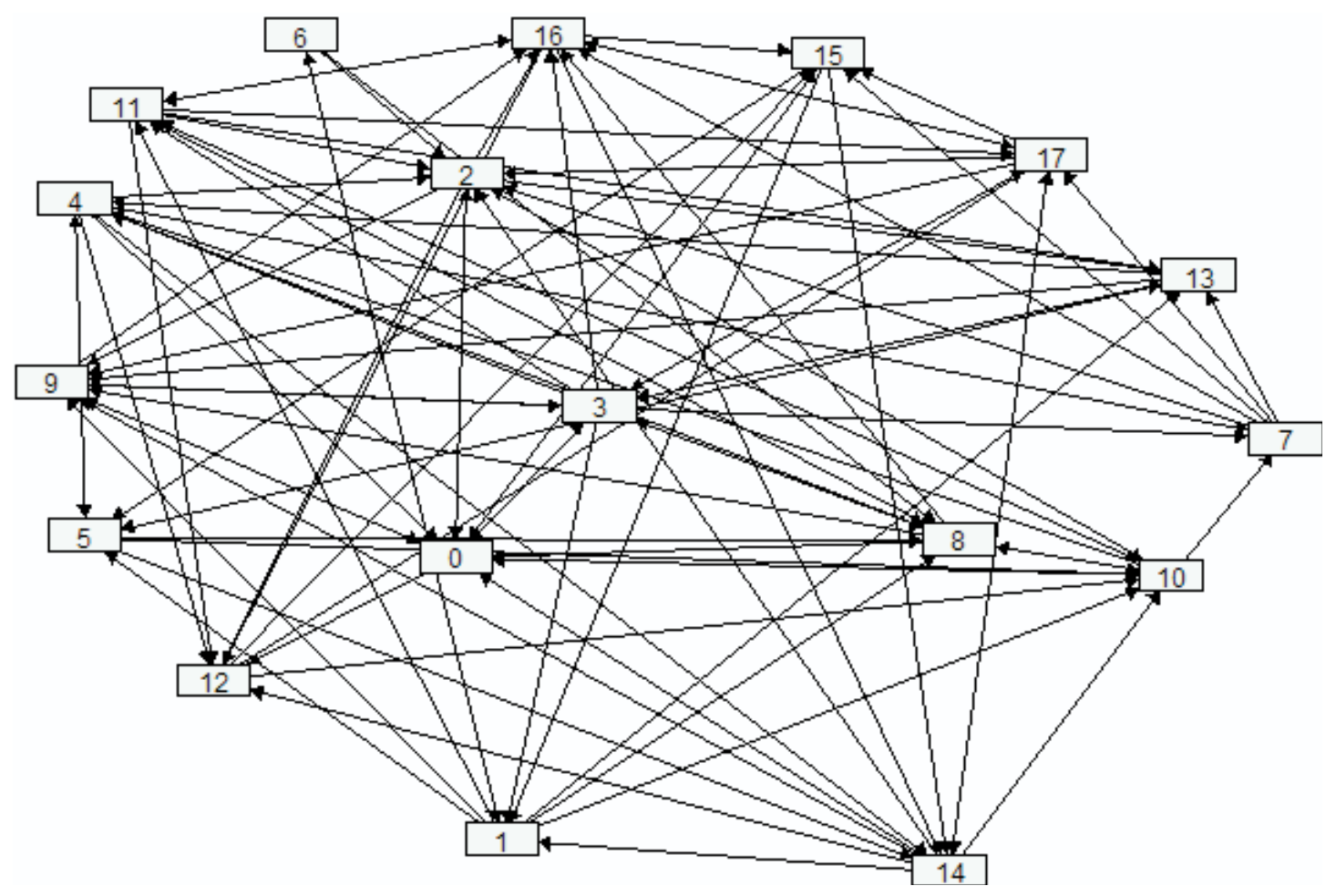

Figura 1 - Gráfico da rede de relacionamentos Fonte: Dados primários (2009). 
Nesta pesquisa, a rede é composta por 17 organizações com até 289 possibilidades de relações entre si, essa diagramação foi realizada com o auxílio do programa GDE - Go Visual Diagram Editor. Hanneman (2001, p. 41) argumenta que "em qualquer rede há (k*k-1) par de ordenados únicos de atores, de modo que $B A$ é divergente de $A B$, no qual $\mathbf{k}$ é o número de atores. Os vínculos predominantes foram o foco deste trabalho, conforme citado no subitem "densidade da rede".

A motivação para o relacionamento diz respeito à socialização dos atores que tendem a interagir com outros que sejam semelhantes nas atitudes, recursos, competências e comportamentos. Dadas essas características, pode-se compreender que as empresas que estejam num mesmo contexto tenham grande simetria em seus perfis, como o ativo e o fluxo de informações. As características semelhantes induzem a um respeito mútuo, evitando a concorrência entre seus pares. Assim sendo, as organizações que são estruturalmente semelhantes terão tendências a não atacar uma à outra, sendo um fator motivador para as relações. (GNYWALI; MADHAVAN, 2001; HALL, 2004). As congêneres são as empresas locatárias do pool, e as estruturas e os produtos comercializados dessas organizações são semelhantes; essas características corroboram os estudos dos autores supracitados. Os participantes da pesquisa declararam que respeito entre eles está em não tentar angariar os clientes um do outro para garantir um relacionamento de boa vizinhança, trocas de informação e favores são constantes, embora sejam realizados na informalidade. A confiança foi citada pelas empresas como fator preponderante para a solidez do relacionamento, afirmando que, quando há confiança, há facilidade de aproximação e, consequentemente, relacionamento entre elas.

A base predominante dos relacionamentos interorganizacionais certamente varia de empresa para empresa. Esta variação foi percebida nas respostas à questão: "Como você qualifica a base predominante dos relacionamentos mantidos entre a sua organização e as outras organizações do pool? Dadas as opções amizade, confiança status, política e econômica, os entrevistados optaram por amizade e confiança. Esses atributos são enfatizados, pois, mesmo quando não apresentados em questionários, eram citados como fator condicionante para a manutenção dos relacionamentos.

A escolha dos relacionamentos está embasada na centralidade e frequência em suas relações. Nas entrevistas e observações, foram constadas essas frequências e a acessibilidade entre seus pares apontando a existência de um padrão informal normativo de trocas de informações e favores. Nessa análise, foi observada a dominância da empresa $\mathbf{Q}$ sobre as demais. Possivelmente pelo seu porte, pois é a maior das três empresas, esse tipo de dominância foi observado por Granovetter (1973), que afirma que quando um ator assume uma posição central na rede, o fluxo de informações, produtos e serviços tendem a ser manipulados por esse ator. $\mathrm{O}$ poder está relacionado a essa dominância. A empresa $\mathbf{Q}$ atende todo o mercado nacional e tem uma parcela significativa na distribuição de combustíveis, enquanto as demais atendem apenas a dois estados da federação. Na troca de favores observada entre esses atores, ficou evidente que as outras empresas (A e $\mathbf{C}$ ) necessitam mais da empresa $\mathbf{Q}$.

A governança é, geralmente, uma expressão para descrever a forma como o negócio é realizado para o público. De acordo com o relato do gerente da UNIBRASPE, o aumento da procura de novos negócios em rede de empresas indica que os novos clientes procuram conhecimentos especializados neste setor. Procuram a satisfação de suas necessidades em um modelo que traduza a construção e requisitos de sua gerência operacional numa perspectiva de melhora dada pelos serviços e informações especializadas na governança da rede. A perspectiva de análise adotada neste trabalho volta-se para a presença de vínculos que caracterizam a frequência nas relações que evidenciem a rede relacional entre as organizações do pool. A qualidade das 
relações e os valores que regem a governança do pool definem os limites de gestão de cada empresa pertencente a esse ambiente. São caracterizados por relações não-hierárquicas, compromissos em longo prazo, múltiplos papéis, responsabilidades, reciprocidade e sentimentos. (GERLACH, 1992).

O relacionamento da UNIBRASPE com as congêneres do pool, segundo a gerência, é totalmente formalizado. Esta política foi adotada como forma de não privilegiar nenhuma das firmas do pool e ter um tratamento uniforme, evitando conflitos entre as empresas dentro da base de distribuição. Essa política também é adotada para as empresas que são sócias no pool, as sócias não dispõem de nenhum privilégio, elas são tratadas como as demais congêneres.

A interferência da administração da UNIBRASPE tanto na fase de compra como de venda, pelas congêneres, é próxima de zero. A política adotada é de que cada empresa administre todo o processo de compra, venda e distribuição dos combustíveis de modo independente e fica a cargo da administração da UNIBRASPE somente o controle dos volumes movimentados pelas firmas como também o controle administrativo do pool. O controle está na segurança, recursos humanos para a consecução dos processos das atividades inerentes ao pool e à administração e controle de qualidade dos produtos por meio do apoio de um laboratório para controle de qualidade dentro da base.

\section{Categorização da evolução das bases da confiança}

Nas sociedades modernas, que se caracterizam por um elevado grau de divisão do trabaIho, é essencial que a troca de informações, pagamentos e materiais sejam organizados eficientemente. Tanto na cadeia vertical, como na horizontal, as relações de confiança e intercâmbios entre essas empresas precisam ser rápidas e fáceis de controlar. Por este motivo, a coordenação de expectativas mútuas desempenha um papel central no relacionamento interorganizacional, e a qualidade da relação social destes é fundamental para o funcionamento dos sistemas socioeconômicos. (BACHMANN, 1999).

A confiança na perspectiva dos envolvidos é suscetível de se desenvolver quando os agentes individuais têm contato face a face e familiarizam-se com cada uma das pessoas. As preferências e interesses não se tornam substancialmente em recursos ou em regime institucional e é compreendido como "a confiança pessoal". A importância da confiança para a construção de um relacionamento mesmo entre as concorrentes do pool é compreendida como essencial para o relacionamento entre as empresas, conforme os relatos dos entrevistados. A confiança interpessoal permite às pessoas correrem riscos, pois confiar está baseado na expectativa do que se vai encontrar no outro e não o que se teme. Assim, a confiança engloba não só as crenças das pessoas sobre os outros, mas também a sua vontade de utilizar o conhecimento adquirido como base para uma ação futura. (McALLISTER, 1995).

As pessoas entrevistadas, quando indagadas se alguma das empresas tem restringido a troca de informações sobre fornecedores e casos de clientes inadimplentes ou, ainda, se essas informações são abertas somente para as empresas em que há um relacionamento mais estreito, responderam que esse tipo de informação é repassado somente para as empresas onde há esse tipo de relacionamento e para aquelas em que mais confiam. Os laços mais fortes entre determinadas empresas é evidenciado quando essas retêm informações, evitando passar para as outras que não pertençam ao grupo. Referente ao código de ética entre as empresas da base, todas responderam que não há um código de ética formalizado, mas existe o respeito entre elas, conforme relato de uma dessas firmas: "Acredito que no quesito de vendas existe o respeito 
pelas bandeiras e por algumas regiões em que determinada empresa atua". O respeito relatado está no lugar da confiança entre elas, pois apontaram que, mesmo sendo concorrentes, uma não ultrapassa os limites da outra em negócios que já estão firmados, mas são livres para a prospecção de novos clientes, mesmo dentro de uma mesma área geográfica.

O respeito referido anteriormente é compreendido melhor quando são observadas as respostas dadas à questão: A palavra confiança tem que significado no que se refere ao relacionamento com as outras empresas? A empresa A pontua que "a confiança é um parceiro entre todos na base"; a C acrescenta que "neste ramo torna-se 90\% de uma negociação"; a organização $\mathbf{Q}$ aponta confiança como base para o relacionamento conforme sua resposta: "em relação às outras empresas que integram o pool não quer dizer muita coisa, pois não há um relacionamento direto entre as empresas, mas em relação à base é fundamental a confiança. Pois confiamos a eles o produto que revendemos aos nossos clientes. É a imagem da empresa que está em jogo". Observa-se que a confiança é compreendida por todos como um elo, tanto para o relacionamento como para fazerem negócios, e é uma condição para a aproximação das empresas. No trabalho de Hosmer (1995, p. 385), há relatos que sustentam o presente estudo, quando afirma que a confiança é descrita como "essencial para a estabilidade das relações sociais", seguido da afirmação de que a confiança "é vital para a manutenção da cooperação e necessária para a interação cotidiana nas relações". Há grande similaridade no que tange à troca de mercadorias e serviços, quando o mesmo autor argumenta que a troca de mercadorias na base da confiança só é possível quando existe confiança pessoal há longa data, e essa é necessária para o sucesso das operações econômicas.

Tal situação foi mencionada pelas três empresas que têm um relacionamento mais próximo ao responderem as perguntas sobre quando se deu o início nos relacionamentos. As três entrevistadas responderam que têm mais de cinco anos de relacionamento, e os motivos que o provocou foram a necessidade de produtos, a amizade de longa data entre eles (os funcionários) e o cumprimento dos acordos estabelecidos entre si. O início e a evolução desses relacionamentos se deram baseados na confiança entre seus pares, pois as negociações e trocas foram realizadas informalmente, sem o conhecimento da matriz de nenhuma dessas empresas, conforme relato dos entrevistados. Nas situações em que há trocas de favores e trocas de informações, a confiança tende a ser o alicerce do relacionamento, e a desconfiança é um atributo que não pode existir nessas relações. Qualquer suspeita sobre a confiança nessas relações pode comprometer o que foi construído ao longo dos anos, e a reconstrução pode não existir e, se houver, a confiança dificilmente será a mesma entre seus pares.

Quando a confiança é destruída, há um colapso no relacionamento, tornando-a imprescindível nas relações sociais. (HOSMER, 1995). A descritiva das empresas sobre a pergunta "Como a confiança pode afetar as atividades na base?" deu-se numa mistura de relações pessoais, com negócios realizados entre as empresas, apontando que desconfiança pode trazer desentendimento. Os relacionamentos seriam abalados, caso não existisse confiança, conforme aponta a resposta da empresa $\mathbf{C}$ - "a confiança é a base de tudo, se não houver confiança no pool, não há porque estarmos aqui, pois é através delas (fornecedoras) que conquistamos a confiança de nossos clientes em ter sempre o produto certo, nas especificações, carregamento correto e na quantidade certa". A empresa A salienta que a confiança deve estar presente "desde o relacionamento pessoal até a retirada do produto". A respondente B confirma o possível colapso explicado por Hosmer (1995) quando afirma que "empréstimos de combustíveis não serão possíveis, pois não haverá confiança nos recebimentos", afirmando uma possível quebra no relacionamento, o que é sustentado pela firma $\mathbf{Q}$ em resposta a pergunta - "surgindo desentendimento e isso seria prejudicial para nós". Houve unanimidade quando se trata da falta de confiança. A ausên- 
cia desse atributo está estreitamente ligada a desentendimento, quebra de contrato e relacionamento. É importante observar que a questão estava relacionada à confiança e como esta poderia afetar as atividades da base, por isso era esperado que todos entendessem como um fator positivo e que poderia trazer redução de custos e bons relacionamentos, por exemplo. No entanto, o que foi observado nas respostas foi uma aversão à falta desse atributo, não se dando conta dos possíveis relacionamentos baseados em confiança.

Há desconfiança numa relação quando os agentes não podem atribuir probabilidades razoáveis nos resultados a serem obtidos. Essa incerteza surge por uma série de razões. Primeiro, a desconfiança surge porque os parceiros são frequentemente incapazes de prever como irá retribuir essa troca ao longo do tempo. Segundo, a natureza das trocas do sistema econômico, no qual as empresas podem responder por esse tipo de incertezas com eliminação de determinadas operações ou por meio da seleção cuidadosa com quem realizará negócios ou trocas. A falta de confiança é subentendida aqui como sendo uma forma de risco relacional, onde existe a perspectiva de que o parceiro não irá cooperar plenamente. A incapacidade dos parceiros preverem o retorno ou custos associados a esses relacionamentos é outro fator de desconfiança. (ADOBOR, 2005).

A descrição dessa situação é percebida na evolução do relacionamento entre as firmas, conforme ilustra a figura 2. Quando descritos por elas sobre a evolução ao longo dos anos, argumentaram que a confiança conquistada entre elas estava sustentada no cumprimento da palavra de cada um.

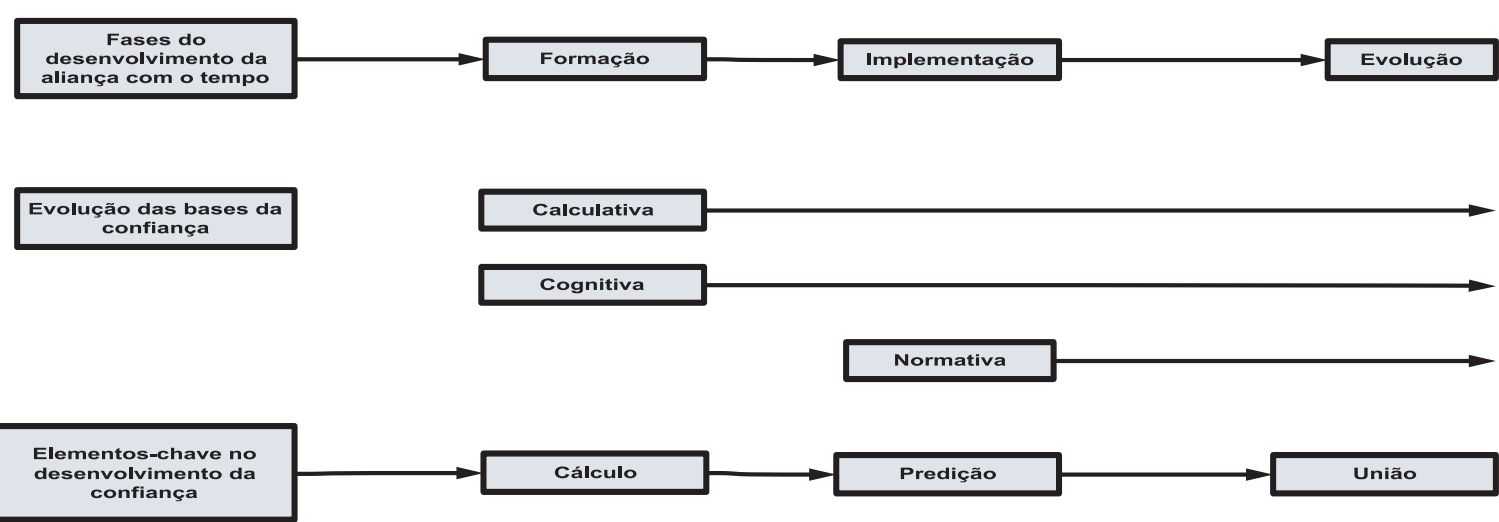

Figura 2 - Fases do desenvolvimento da evolução da confiança na rede.

Fonte: Child (1999).

Essas fases estão contidas em cada uma das estruturas a seguir, pois fazem parte do contexto evolutivo do presente trabalho, logo cada fase será abordada nos subitens seguintes. Na fase da estrutura calculista da confiança, ocorre o processo de formação e escolha dos parceiros para o arranjo dos relacionamentos interorganizacionais, onde são selecionadas as empresas que têm o mesmo perfil e interesses e que poderão ser parceiros cooperativos futuros. A confiança neste estágio é vista como cálculo e implica numa dedução sobre a benevolência da empresa a agir com interesse baseada em valores e objetivos comuns. A construção da confiança implica em um "processo de cálculo" com base na capacidade de a empresa continuar cumprindo suas obrigações e sobre a consideração dos custos versus recompensas para permanecer nesta relação. (BORIES, s/d). Os motivos de cooperação entre as empresas são evidenciados nesta fase e podem ser considerados, entre outros motivos, a redução de custos de transação e as alianças para obtenção de vantagem competitiva. Essa parceria foi evidenciada nos relatos dessas empre- 
sas que cooperam entre si na distribuição de combustíveis, conforme declaração a seguir:

\begin{abstract}
Se a minha empresa vai fazer uma entrega para um determinado local e a carga não está completa e tem uma das 'nossas' que precisa fazer uma pequena entrega na mesma região, então completamos a carga com o produto dela e fazemos a entrega. A ajuda nesse caso é mútua. Resolvemos o problema dos dois, pois aproveito toda a capacidade do caminhão e diluímos proporcionalmente o frete e cumprimos o compromisso com o cliente de entregar na data combinada.
\end{abstract}

A eficácia da confiança depende da sua distribuição. A confiança horizontal está associada à busca de um acordo entre os indivíduos pertencentes à mesma categoria. É uma fonte de oportunismo coletivo, uma vez que incentiva o alinhamento dos indivíduos. As relações de cooperação podem ser compreendidas no nível horizontal, como alocação de custos e controle na tentativa de refrear o oportunismo. Quanto mais horizontal for a confiança, mais necessário e oneroso deverá ser o sistema de vigilância. A relação entre confiança, oportunismo e de controle depende da natureza da relação de confiança. (BORNAREL, 2004).

A confiança vertical foi pontuada, no relato anterior da cooperação de frete, e foi observado, na pesquisa, que é uma prática comum entre as empresas com maiores afinidades. Esse processo de colaboração é resolvido informalmente e está baseado na confiança e no relacionamento interpessoal desses atores. É interessante observar que parece haver a separação da empresa e dos indivíduos nessas atitudes; como agem na informalidade; a confiança está relacionada à outra pessoa e não à empresa que ele representa. Child (1999) evidencia esse fenômeno quando afirma que a confiança interpessoal e sua qualidade nessas relações "interorganizacionais", pois os membros dessas organizações agem como verdadeiros guardiões da confiança criada por eles. Dessa forma a produção da confiança surge pelo reforço mútuo de investimentos nesse atributo e pela qualidade da cooperação a ela associada. Esse processo de colaboração e confiança mútua é criado ao longo dos anos, conforme os informantes, pois não têm esse tipo de relacionamento com todas as congêneres e sim com as empresas selecionadas por cada um. Essa seleção está embasada em trocas de experiências passadas e na possibilidade de trocas futuras, num continuum dessas relações. Para que haja essa construção, os atores apoiam-se em inúmeros fatores regidos pelo ambiente de construção desses relacionamentos.

A estrutura cognitiva da confiança refere-se à percepção, à imaginação, à linguagem, à concepção e ao pensamento dos atores de um ambiente. A perspectiva cognitiva procura compreender a multiplicidade das emoções dos atores envolvidos em forma de empatia. É uma forma de reconhecer a importância dos diversos caminhos que os atores devem percorrer para construir a sua realidade social numa formação da percepção e a compreensão clara dos valores e dos processos sociais. (SONPAR; HANDELMAN; DASTMALCHIAN, 2003). Nessa fase, há a implantação dos relacionamentos e a confiança neste estágio é mais cognitiva. Há a construção do conhecimento entre seus pares e pode adquirir um caráter preditivo em relação ao conjunto de atitudes e reações dos atores em face ao ambiente dos demais com as informações adquiridas e acumuladas num determinado espaço de tempo. Um fluxo de informação toma como premissa que a cognição dos atores da rede fixa a interação, e interação, por sua vez, causa as alterações da rede. As variantes - informações - é que especificam as consequências das percepções dos atores da rede. Por exemplo, percepções precisas de poder ou uma percepção cognitiva desenvolvida pelos integrantes da rede. A posição hierárquica é um condicionante da personalidade e comportamento de seus pares. A evolução cognitiva está, então, relacionada ao acúmulo de conhecimentos dos processos e de poder, no conhecimento mais profundo dos seus parcei- 
ros, diminuindo as incertezas nas ações futuras (previsibilidade). Baseia-se, essencialmente, sobre as suas percepções, inferências e conjeturas que os levam à formação e compreensão do ambiente onde está inserido. Essa análise é associada à constituição social da confiança, pois ela é, necessariamente, percebida e fortalecida por meio da interação social. (RODRIGUES, 1999).

Na estrutura normativa da confiança, as escolas tradicionais vêem-na como "boa" e desconfiança como "ruim". Muitos pesquisadores compreendem a desconfiança como um distúrbio psicológico e que deve ser corrigido na tentativa de resolver situações que podem se tornar conflituosas, a fim de promover uma colaboração efetiva entre seus pares caracterizados pela ação da confiança. Assim, a confiança pode ser compreendida como um ingrediente necessário para manter a ordem social, ou seja, normas. (LEWICKI; MCALLISTER; BIES, 1998). Nessas relações, a confiança reproduz um conjunto de valores institucionalizados que depende do compartilhamento de valores comuns entre as pessoas, isto é, normas que tornam estáveis as interações sociais. Nelas se constrói um quadro de partilha de obrigações e expectativas em que os atores sociais possam investir, numa função integradora de confiança e controle. (RODRIGUES, 1999; REED, 2001).

O gerente da UNIBRASPE afirma, em seu relato, que a empresa não dispensa nenhum tratamento especial a qualquer uma das empresas pertencentes ao pool e que todo relacionamento é totalmente formalizado. Cunha e Marlene (2004) afirmam, em seus estudos, que "os contratos formais desempenham um papel importante no estabelecimento de condições e critérios de desempenho para colaboração e podem prover a única base em que os parceiros de negócios são preparados para trabalhar juntos num primeiro momento". Essa normativa da UNIBRASPE tem por objetivo instituir a confiança baseada em normas, não provendo diferenciação nos relacionamentos e normalizando qualquer tipo de relacionamento com as demais inquilinas. Cunha e Marlene (2004) argumentam que os contratos raramente são suficientes sozinhos e que o entendimento informal, baseado na confiança, frequentemente provê um fator ainda mais poderoso na determinação de como colaborar. Essa narrativa é sustentada nas declarações dos informantes ao afirmarem que os empréstimos de produtos e as suas relações são informais, com normas também informais instituídas e respeitadas por eles.

Essa afirmação é sustentada no trabalho de Bornarel (2004), para quem, na construção da cooperação, não devem existir instrumentos de controle formal. Esse mesmo autor distingue confiança em duas formas: a confiança horizontal e vertical. A confiança é horizontal quando é dividida entre pessoas que pertencem ao mesmo nível hierárquico. Nesse perfil está o relacionamento da gerência da UNIBRASPE com os gerentes das congêneres, onde o relacionamento é totalmente formalizado, para sustentar a relação de confiança, num padrão de atendimento para todas as congêneres. No relacionamento vertical, a confiança é dividida entre as pessoas localizadas em diferentes níveis hierárquicos e pode ser relacionado às interações de relacionamentos entre os funcionários das congêneres onde ocorrem empréstimos de produtos e trocas de informações, promovendo a reciprocidade de favores. Nessa segunda distinção, existe um conjunto composto por ambas, onde há uma combinação dessas relações nos diversos níveis hierárquicos nas empresas que compõem o pool estudado.

Essa troca de favores está relatada na cognição, em que a seleção das parceiras está embasada nas trocas de experiências passadas e na possibilidade de trocas futuras num continuum dessas relações. Está relatado também na troca de favores de fretes entre as parceiras para uma mesma localização geográfica. Reed (2001) descreve tal quadro como a "regra da reciprocidade", em que é estabelecida uma configuração estável de direitos e obrigações com base nos princípios da reciprocidade normativa - ajudo aqueles que me ajudam -. Essa normativa é um mecanismo de construção da confiança que estabiliza e mantém sistemas sociais. Entende-se, 
então, que normas são instituídas para gerar confiança e que, sozinhas, são insuficientes para o bom andamento da governança. Entende-se também que a informalidade é a base efetiva dos relacionamentos entre as empresas, nas quais a confiança é sustentada pelas normas informais criadas por seus atores.

\section{CONCLUSÕES E RECOMENDAÇÕES}

Novas estratégias foram implantadas para a adaptação dessas empresas ao novo cenário competitivo organizacional. A estratégia adotada no pool é a colaborativa, na qual a estrutura organizacional favorece esse tipo de relacionamento entre as congêneres, pois essas têm os mesmos propósitos e os objetivos são comuns. Nessa prática colaborativa está a soma dos capitais das empresas fundadoras do pool para a consecução do projeto idealizado por elas, pontuando que sozinhas não conseguiriam realizar o projeto devido ao alto custo das obras e implantação da unidade.

Nessas relações foram constatados dois aspectos importantes em relação à confiança. $\mathrm{O}$ primeiro foram as normas, como base da confiança instituída pela UNIBRASPE, proprietária e administradora do pool. Observa-se, nesse cenário, a confiança normativa, a formalização como base da confiança numa evidência para todas as empresas de que a equidade nos relacionamentos é instituída por leis e normas próprias da administradora e aplicadas a todas as congêneres sem distinção. O segundo aspecto importante apontado pela pesquisa foi a acentuada informalidade nas relações entre as congêneres. A confiança foi um atributo evidenciado por todas as empresas em toda a cadeia de relacionamento e considerado um fator condicionante para o relacionamento. A formação deste cenário se deve à estrutura da rede estudada e à disposição de vizinhança entre seus pares. Foi observado que quanto mais próximas as empresas, mais o ambiente fica favorável para o relacionamento interorganizacional.

A motivação para o relacionamento diz respeito à socialização dos atores que tendem a interagir com outros que sejam semelhantes nas atitudes, recursos, competências e comportamentos. A pesquisa apontou que o respeito mútuo entre as organizações, troca de favores recíprocos e a confiança nos relacionamentos foi citada como os principais fatores motivadores para os relacionamentos. Essas motivações são o suporte que define a base predominante nos relacionamentos, conforme os relatos dos informantes que indicaram a amizade de longa data e a confiança entre seus pares como essas bases. O mecanismo de governança da UNIBRASPE volta-se para a presença de vínculos que caracterizam a frequência nas relações que evidenciem a rede relacional entre as organizações do pool.

A pesquisa sobre a categorização da evolução das bases de confiança entre as empresas do pool procurou ter o ponto inicial o conceito em si da palavra. Abrindo para um leque de interesses, apontado pela pesquisa na busca da compreensão da evolução da confiança nos aspectos cognitivo, normativo e calculista entre seus atores. Foi observada também a troca mútua de favores e confiança num intuito de ajuda e minimização de custos. A abordagem sobre a confiança e desconfiança no ambiente estudado na pesquisa apontou a confiança como fator principal para um bom relacionamento. Esse atributo deve estar presente em toda fase de qualquer negociação informal entre eles, obedecendo a um código de ética também informal e instituído por eles. A quebra de qualquer um dos elos desse acordo pode ter punições severas, e a desconfiança não é tolerada por nenhum deles, conforme seus relatos. A empresa que descumprir o acordo pode ficar isolada e não mais fazer negócios ou obter ajuda de nenhuma outra congênere 
do pool. Quanto à reconstrução da confiança, num caso de quebra, as entrevistas demonstraram que algumas empresas foram totalmente intolerantes e não aceitariam a reconstrução. Outras argumentaram que se, por acaso, houvesse a reconstrução, jamais a confiança seria a mesma do início do relacionamento.

As trocas de favores observadas foram a substituição de pessoal em períodos de férias por outro da concorrente em qual se confia, a partilha de fretes para uma mesma região geográfica para a redução de custo e aproveitamento total da capacidade de carga e empréstimos de produtos. A estrutura cognitiva da confiança foi relacionada com as interações entre seus pares e o acúmulo de conhecimentos dos processos. Quanto ao poder como um condicionante comportamental, a pesquisa apontou que quanto maior a posição hierárquica maior a formalidade nos relacionamentos. Quanto à estrutura normativa da confiança, existem dois fatores importantes percebidos na pesquisa. O primeiro está relacionado num conjunto de valores e normas institucionalizadas pela administradora para garantir interações sociais estáveis num intuito de construir um quadro em que as expectativas dos atores sociais possam ser supridas. $\mathrm{O}$ segundo é a percepção de normas informais e de grande influência nos relacionamentos entre as empresas.

Observou-se que os esforços coordenados numa associação de fatores que levam a um objetivo comum foram notadamente refletidos nas relações e ações dos atores da rede estudada. Essa possibilidade apoiou-se na estruturação de uma rede bem definida, o que tornou possível de serem reveladas por meio da análise de redes. E, por fim, em observação aos relacionamentos interorganizacionais estudados, parece que há uma grande simetria nos relacionamentos formalizados e informais, esse último age como complemento do primeiro para a garantia da boa vizinhança percebida no pool.

\section{REFERÊNCIAS BIBLIOGRÁFICAS}

ADOBOR, H. Optimal trust?: uncertainty as a determinant and limit to trust in inter-firm alliances. Hamden, Connecticut, USA: Department of Management, School of Business, Quinnipiac University, 2005.

ANP. Agência Nacional do Petróleo, Gás Natural e Biocombustíveis. Superintendência de Abastecimento. Portaria ANP 116/00. Disponível em: <http://www.anp.gov.br>. Acesso em: 25 jan. 2009.

AMATO NETO, J. (Org.). Redes entre organizações: domínio do conhecimento e da eficácia operacional. São Paulo: Atlas, 2005.

BACHMANN, R. Trust, power and control in transorganizational relations. SASE - conference. Madison/Wisconsin, USA, 1999.

BENGTSSON, M.; KOCK, S. Cooperation and competition in relationships between competitiors in business networks. Jounal of Business \& Industrial Marketing, v. 14, n.3, p.178-193, 1999.
BORIES, D. La confiance dans les relations acheteur-vendeur: le rôle moderateur du cycle de vie relationnel. Doctorant sous la direction du Professeur Eric Vernette IAE Toulouse.

BORNAREL, F. La confiance contrainte. In: CONFÉRENCE DE L'ASSOCIANTION INTERNATIONALE DE MANAGEMENT STRATÉGIQUE, 13., 2,3 et 4 juin 2004, Normandie, Vallé de Seine: Université de Créteil - Val de Marne, 2004. p.1-25.

BRUSCO, S. The Emilian model: productive decentralization and social integration. Cambridge Journal of Economics, v.6, p. 167-184, 1982.

BURT, R. S. Network structure of social capital. Chicago: University of Chicago and Institute Européen d'Administrtion d'affaires (INSEAD), july, 2000. p. 35.

CASTELLS, M. A sociedade em rede - a era da informação: economia, sociedade e cultura. 10. ed. São Paulo: Paz e Terra, 2007. 
CHILD, J. Confiança e alianças estratégicas internacionais: o caso das joint ventures sinoestrangeiras. In: RODRIGUES, S. B. (Org.). Competitividade, alianças estratégicas e gerência internacional. São Paulo: Atlas, 1999.

COSER, C. Relações interorganizacionais e estruturas institucionais: um estudo no espaço social de Videira. 2003. 339f. Dissertação (Mestrado em Administração)-Universidade Federal do Paraná, Curitiba, 2003.

CRESWELL, J. W. Projeto de pesquisa: métodos qualitativos, quantitativos e misto. 2. ed. Porto Alegre: Artmed, 2007.

CUNHA, Cleverson Renan da. A confiança nas relações interoganizacionais cooperativas: Estudo múltiplo de casos em empresas de Biotecnologia no Brasil. Belo Horizonte, 2004. 283 f. Tese (Doutorado em Administração)-Centro de PósGraduação e Pesquisa em Administração, Universidade Federal de Minas Gerais, Belo Horizonte, 2004.

CUNHA, C. R.; MARLENE, M. C. O. L. A confiança nas relações interorganizacionais. In: O\&S Organizações e Sociedade, Salvador, v.11, Edição Especial, p. 79-93, 2004.

DAS, T. K. Strategic alliance temporalities and partner opportunism. British Journal of Management, v. 17, p. 1-21, 2006.

DERBEL, Walid; AMMAR MAMROUK, Zeineb Ben. Le dileme de la confiance et de la coopération: interdépendance dês acteurs et suprématie Du système organisationnel. La Revue des Sciences de Gestion, Direction et Gestion, n. 204, p. 63-88, Déc. 2003.

EMIRBAYER, M.; GOODWIN, J. Network analysis, culture, and the problem of agency. The American Journal of Sociology, v. 99, n. 6, p.1411-1454, May 1994.

FERREIRA, Aurélio B. de Holanda. Novo dicionário Aurélio da Língua Portuguesa. 3. ed. Curitiba: Positivo, 2004.

GDE. Go Visual Diagram - diagram editor. Version 1.3.1. Oreas GMBH. Köln, Germany, 2009.
GNYAWALI, D. R.; MADHAVAN, R. Cooperative networks and competitive dynamics: a strutuctural embeddedness perspective. Academy of Management Rewiew, v.26, n. 3, p. 431-445, 2001.

GERLACH, M.L. Alliance capitalism. Berkeley: University of California Press, 1992.

GRANOVETTER, M. S. The strength of weak ties. American Journal of Sociology, v. 78, n. 6, p. 136080, 1973.

HALL, R. H. Organizações: estrutras, processos e resultados. 8. ed. São Paulo: Pearson, 2004.

HANNEMAN, Robert. Introduction to social network methods. Riverside: University California, 2001.

HOSMER, L. T. Trust: the connecting link between on organizational theory and philosophical ethics. Academy of management Rewiew, v. 20, p. 379403, 1995.

KANTER, R. M. When giants learn cooperative strategies. Planning Rewiew, v. 18, n. 1, p. 15-22, Jan./Feb. 1990.

KNOKE, D. Political networks: the structural perspective. Cambridge: Cambridge University Press, 1994.

KOTTER, J. P. Managing external dependence. Academy of Management Review, v. 4, n.1, p. 87 92, 1979.

LEWICK, R. J.; MCALLISTER, D.J.; BIES, R. J. Trust and distrust: new relationships and realities. Academy of Management Review, v. 23, n. 3, p. 438-458, 1998.

MALAFAIA, G. C. et al. Capital social e a construção da confiança em redes de cooperação: mudando padrões de relacionamentos na pecuária de corte. In: ENCONTRO DA ANPAD, 31., 22-26 set 2007, Rio de Janeiro. Anais... Rio de Janeiro: ANPAD, 2007. p. 22-26.

MARSHALL, A. Os economistas: princípios de economia - tratado introdutório. São Paulo: Nova Cultural, 1996. 
McALLISTER, D. J. Affect - and cognition - based trust as foundation for interpersonal cooperation in organizations. Academy of Management Journal, v. 38, n.1. p. 25-59, 1995.

MICHAELIS. Dicionário eletrônico: versão 5.0. DTS Software Ltda, 1998.

MOTTA, F. C. P.; CALDAS, M. P. (Org.). Cultura organizacional e cultura brasileira. São Paulo: Atlas, 1997.

PFEFFER, J.; SALANCIK, R. G. The external control of organizations: a resource dependence perspective. New York: Harper \& Row, 1979.

QUERE, L. La structure cognitive et normative de la confiance. Réseaux, v. 4, n. 108, p. 125-152, 2001.

REED, M. I. Organization, trust and control: a realist analysis. Lancaster, UK: Lancaster University Management School, 2001.

RIOLO, R. L.; COHEN, M. D.; AXELROLD, R. Evolution of cooperation without reciprocity. Nature, v. 414, 22 nov. 2001.

RODRIGUES, S. B. (Org.). Competitividade, alianças estratégicas e gerência internacional. São Paulo: Atlas, 1999.

ROSSETTO, C. R.; ROSSETTO, A. M. As perspectivas institucional e da dependência de recursos e o processo de adaptação estratégica organizacional. NIPEM - Núcleo Interdisciplinar de Pesquisa em Estratégia e Mudança Organizacional, v.7, n.12 p.111-136, maio 1999.
SCOTT, J. Social network analysis: a handbook. 2 ed. London: Sage, 2000.

SONPAR, K.; HANDELMAN, J.; DASTMALCHIAN. Trust, organizational change and institutionalization: a study of health care delivery transformation in Southern Alberta. Victoria, Canadá: University of Victoria, 2003.

WILLIAMSON, O. E. The economic institutions of capitalism: firms, markets, relational contractin. London: Yale University; Collier Macmillan Publisher,1985. p.15-35.

XAVIER, L. Vers une conception renouvelée de la confiance: le cas de la relation entre l'enseigne Auchan et ses fournisseurs. In: CONFÉRENCE INTERNATIONALE DE MANAGEMENT STRATÉGIQUE, 16., 6-9 Juin 2007, Montréal: Université Montesquieu-Bordeaux IV. Pôle Universitaire de Sciences de Gestion. p. 6-7. 